\title{
Correction to: Antimicrobial Drugs Encapsulated in Fibrin Nanoparticles for Treating Microbial Infested Wounds
}

B. Maria Alphonsa ' • P. T. Sudheesh Kumar' • G. Praveen ' • Raja Biswas ' K. P. Chennazhi' • R. Jayakumar'

(C) Springer Science+Business Media, LLC, part of Springer Nature 2019

Correction to: Pharmaceutical Research, (2014) 3I(5): |338-5 I

https://doi.org/ I0.1007/s I 1095-0 I 3-1 254-6

In the original manuscript, the Fig. 2 a-i is inadvertently repeated as Fig. 2 a-ii. This mistake has been rectified and the corrected Fig. 2 is presented below.

The online version of the original article can be found at https://doi.org/l0. |007/s | |095-0|3-1254-6

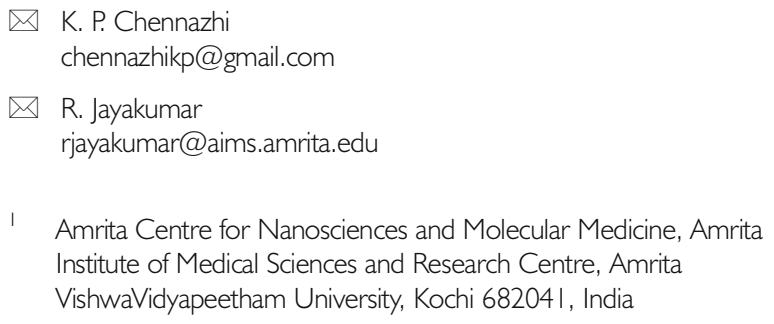


Fig. 2 (a) SEM images of (i) Ciprofloxacin loaded fibrin nanoparticles (CFNPs) (ii) Fluconazole loaded fibrin nanoparticles (FFNPs). (b) FT-IR spectra of control drugs and drug loaded fibrin nanoparticles.

\section{a}
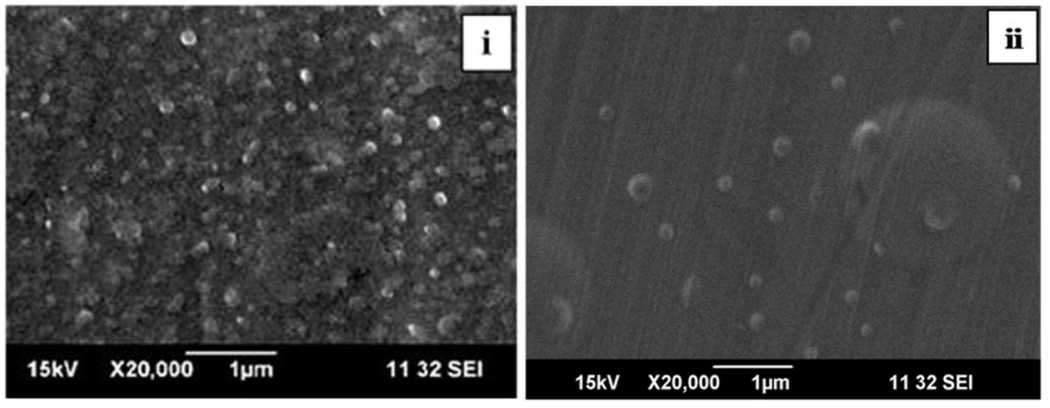

b

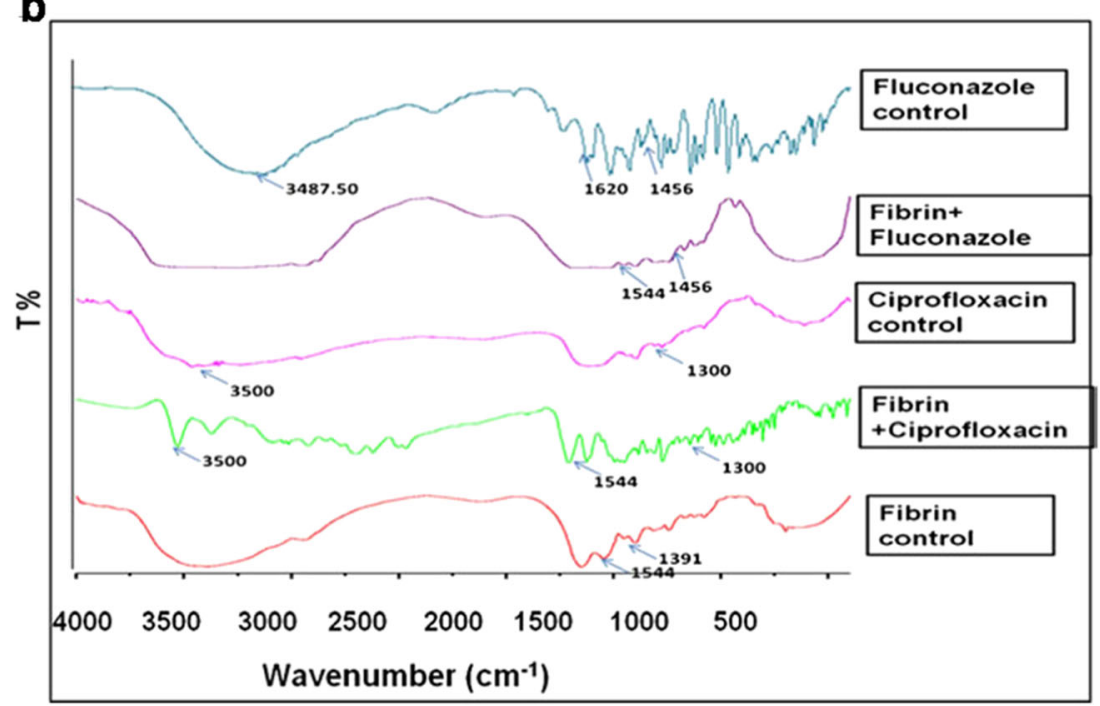


Similarly, Fig. 10 (ii) a and (iii) a have been inadvertently repeated. This mistake has been rectified and the corrected Fig. 10 is presented below.

(i)
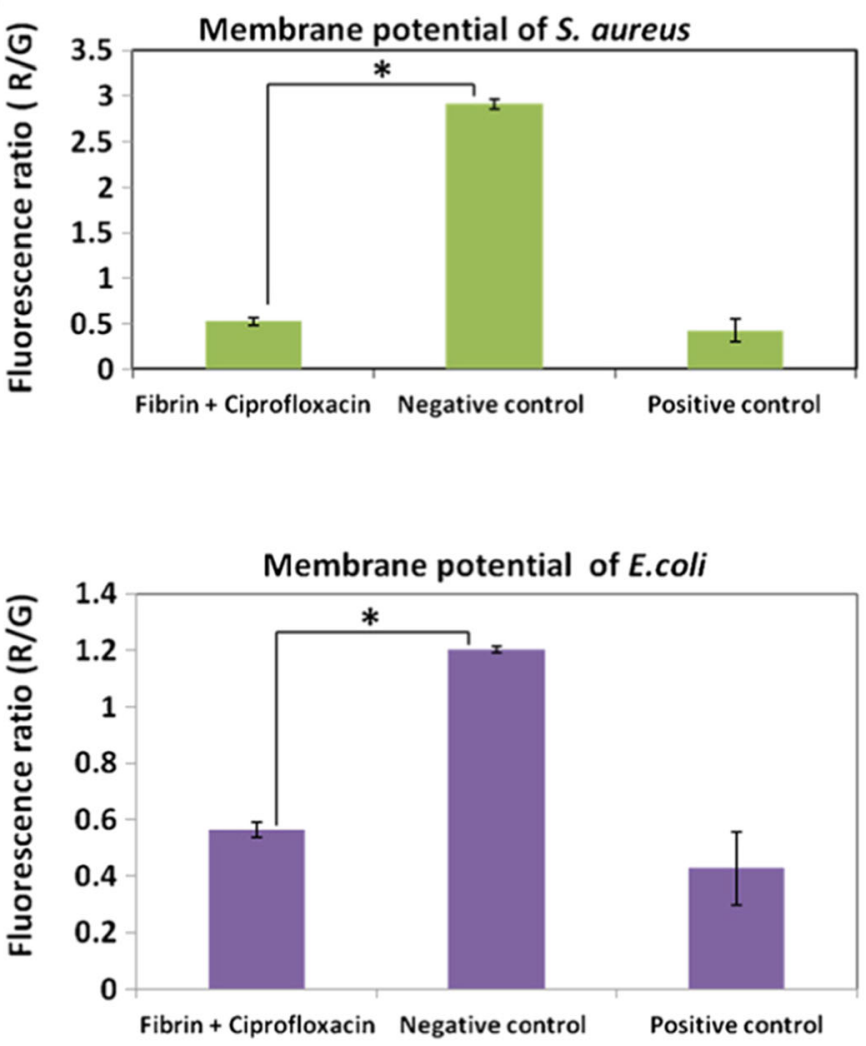

(ii)

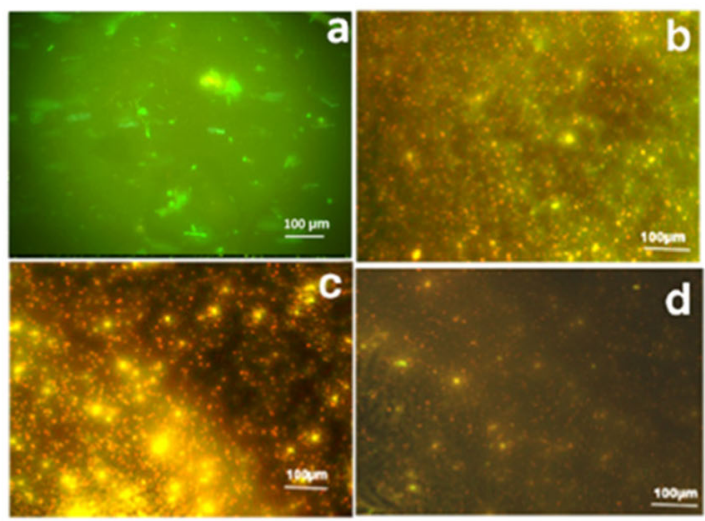

(iii)

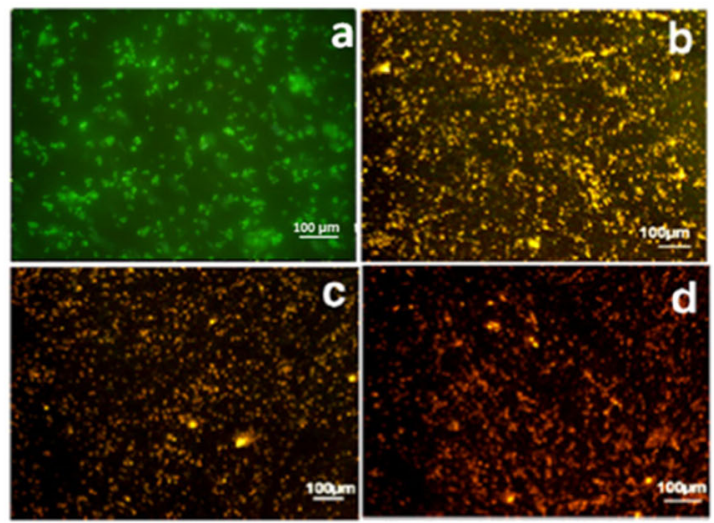

Fig. 10 (i) Membrane potential evaluation of the CFNPs against S. aureus and E. coli. (ii) Live Dead assay of E. coli: (a) E. coli control (b) fibrin + ciprofloxacin $(33 \mu \mathrm{g})(\mathbf{c})$ fibrin + ciprofloxacin $(66 \mu \mathrm{g})(\mathbf{d})$ Fibrin + ciprofloxacin $(99 \mu \mathrm{g})$. (iii) Live Dead assay of S. aureus: (a) S. aureus control, (b) fibrin + ciprofloxacin (33 $\mu \mathrm{g})$, (c) fibrin + ciprofloxacin $(66 \mu \mathrm{g})$, (d) fibrin + ciprofloxacin $(99 \mu \mathrm{g})$.

In the original manuscript Fig. 11, (v) d has also been inadvertently repeated in Fig. 11, (vi) b. This mistake has been rectified and the corrected Fig. 11 is presented below. 

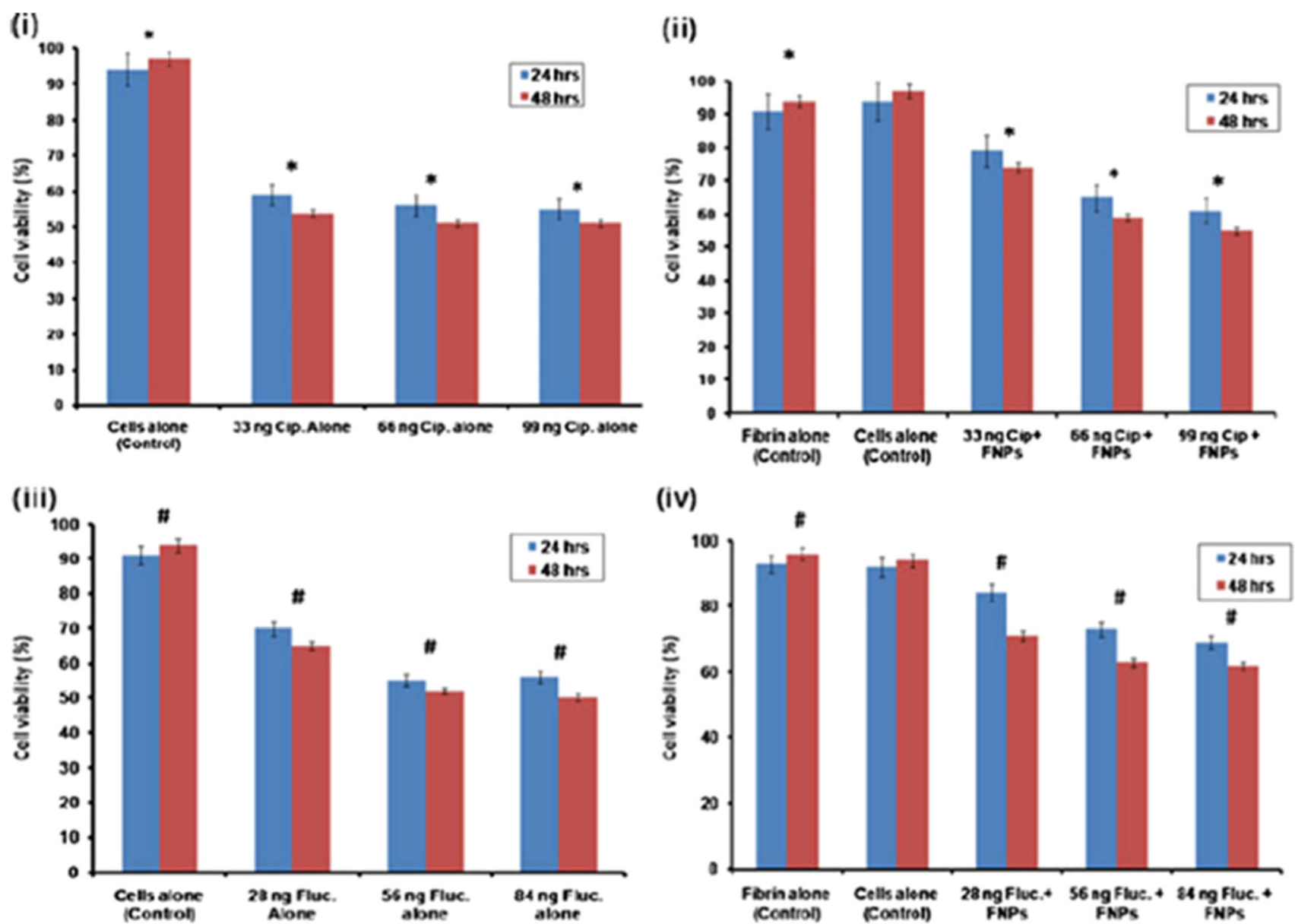

(v)
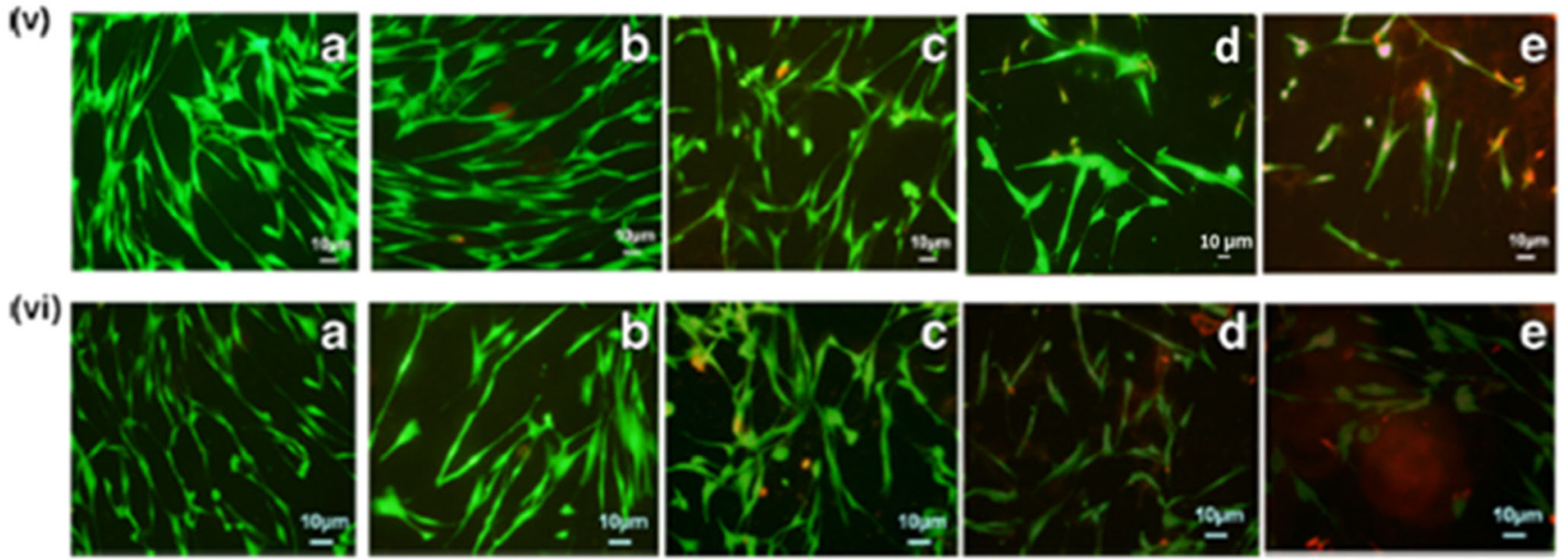

Fig. I I Cell viability studies of the antibacterial and antifungal drug loaded nanoparticles plotted as percentage of viability in HDF Cell lines (i, ii) Three different concentrations of bare and ciprofloxacin loaded fibrin nanoparticle systems. $*(p<0.05)$ statistical significance compared to controls (iii, iv) Three different concentrations of bare and fluconazole loaded fibrin nanoparticle systems Positive control. \# $(p<0.05)$ statistical significance compared to controls $(\mathbf{v})$ Live dead staining of Ciprofloxacin loaded fibrin nanoparticles: (a) control HDF cells (b) Fibrin control (c) Fibrin $+33 \mu \mathrm{g}$ Ciprofloxacin, (d) Fibrin+66 $\mu \mathrm{g}$ Ciprofloxacin, (e) Fibrin $+99 \mu \mathrm{g}$ Ciprofloxacin. (vi) Live dead staining of Fluconazole loaded fibrin nanoparticles: (a) control HDF cells (b) Fibrin control (c) Fibrin $+28 \mu \mathrm{g}$ Fluconazole, (d) Fibrin $+56 \mu \mathrm{g}$ Fluconazole, (e) Fibrin $+86 \mu \mathrm{g}$ Fluconazole.

These changes in the figures would not affect the overall conclusion of the whole manuscript. The authors would like to apologize for any inconvenience caused.
Publisher's Note Springer Nature remains neutral with regard to jurisdictional claims in published maps and institutional affiliations. 